\title{
An Interventional Study on Antibiotic Cement-coated Nails and Cement Beads in the Management of Infected Nonunion of Long Bones
}

\author{
Prabhat Agrawal ${ }^{1}$, SV Sunny Deol ${ }^{2}$, N Rajkumar $^{3}$, V Arul Jothi $^{4}$, SM Murali ${ }^{5}$
}

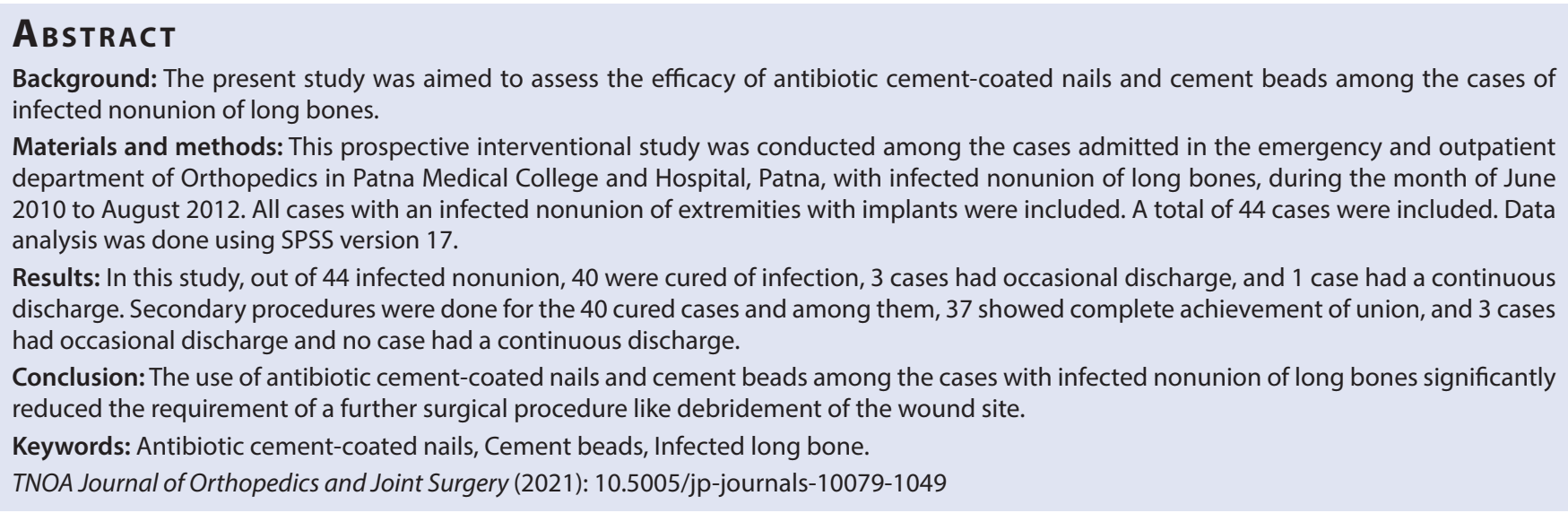

\section{INTRODUCTION}

In the past decades, the incidence of infected nonunion shows a steady increase due to a high rate of trauma from road traffic accidents, industrial injuries leading to open fractures, postoperative infection following open reduction and internal fixation (ORIF), and injurious use of antibiotics resulting in resistant strains of bacteria when compared with past when chronic osteomyelitis was the major cause of infected nonunion. ${ }^{1}$

Causes of infected nonunion are usually inherent to the fracture, like an open wound, loss of soft tissue or bone, severe comminution and gross displacement, vascular compromise, deep-seated infection at fracture area, periosteal stripping, etc. ${ }^{2}$ In infected nonunion, secondary infections are common and multiple organisms may grow from cultures taken from sinus tracts and open biopsy specimens of surrounding soft tissue and bone.

Traditionally, the treatment strategy has been a two-staged procedure. The first stage was to control infection that occurred at the fracture site and the second stage involved procedures to achieve bone union. The control of infection requires repeated debridement, intravenous antibiotics ${ }^{3}$ along external stabilization. Once the infection has been eradicated secondary procedures like the opening of the medullary canal, freshening of fracture ends, proper reduction of the fracture, internal or external stabilization, and cancellous and/or cortical bone grafting are done to achieve union at the fracture site.

Buchholzand Engelbrecht ${ }^{4}$ reported that penicillin, erythromycin, and gentamicin incorporated into the cement used to attach total hip joint prostheses, diffused out into surrounding tissues over a period of months, thereby providing prolonged concentrations of local antibiotic. Klemm ${ }^{5}$ used gentamicin-impregnated cement into
${ }^{1}$ Department of Orthopaedics, All India Institute of Medical Sciences, Patna, Bihar, India

2,5Department of Orthopaedics, Sri Muthukumaran Medical College Hospital, Chennai, Tamil Nadu, India

${ }^{3}$ Dhanalakshmi Srinivasan Medical College and Hospital, Perambalur, Tamil Nadu, India

${ }^{4}$ Department of Ortho, OMS Hospital, Chennai, Tamil Nadu, India

Corresponding Author: SM Murali, Department of Orthopaedics, Sri Muthukumaran Medical College Hospital, Chennai, Tamil Nadu, India, Phone: +91 9445373395, e-mail: Muraliorth@gmail.com

How to cite this article: Agrawal P, Sunny Deol SV, Rajkumar N, et al. An Interventional Study on Antibiotic Cement-coated Nails and Cement Beads in the Management of Infected Nonunion of Long Bones. TNOA J Orth Joint Surg 2021;3(2):76-79.

Source of support: Nil

Conflict of interest: None

beads and used these to temporarily fill in the dead space created after the debridement of infected bone.

Single-staged procedures such as debridement and application of Ilizarov fixator ${ }^{6,7}$ or use of antibiotic cement-impregnated intramedullary nails (ACIINs) ${ }^{8,9}$ have been described. The llizarov ring fixator has been used after debridement for bone transport or corticotomy distraction after acute docking. This procedure is technically demanding and has significant complications and is best suited for large segmental bone defects $s^{6,7,10,11}$

Antibiotic cement-coated nail and antibiotic cement beads are considered as one of the options for treating the infected long bones and also provide better stability to the injured long bone. ${ }^{8,9}$ 
Use of antibiotic cement-coated nail can allow early weight-bearing and also it reduced the complications associated with fixator, such as infection of the pin tract, stiffness of the joints, etc. Hence, this study was conducted to assess the efficacy of antibiotic cementcoated nails and cement beads in cases of infected nonunion of long bones.

\section{Materials and Methods}

This prospective interventional study was conducted among the cases admitted in the emergency and outpatient department of Orthopedics in Patna Medical College and Hospital, Patna with infected nonunion of long bones, during the month of June 2010 to August 2012. All cases with an infected nonunion of extremities with implants in situ were also included in the study. Patients with non-infected nonunion, open physis, infected nonunion with bone gap $>4 \mathrm{~cm}$ after debridement, and patients with diabetes mellitus, tuberculosis, and HIV were excluded from the study. Hence, a total of 44 cases were included in this study.

The study was approved by the ethical committee of this institution. Informed consent was obtained from the patients, before starting the study. A thorough history was taken to determine if the patient has a history of allergy to antibiotics so that those antibiotics were not used when mixing it with the bone cement. The evaluation of intraoperative culture and sensitivity results guides the selection of the appropriate postoperative intravenous antibiotics.

Preoperative radiographs were taken which helps the operating surgeon to assess the size of the intramedullary nail needed.

The length of the intramedullary nail is determined as follows:

- For K-nail-from the tip of the greater trochanter to the upper border of patella plus $2 \mathrm{~cm}$.

- For V-nail from the tip of the upper end of the fibula to medial malleolus minus $2 \mathrm{~cm}$.

- The diameter of both $\mathrm{K}$-nail and V-nail is selected $2 \mathrm{~mm}$ less than the maximum size reamer used as a further $2 \mathrm{~mm}$ is makeup by the coating of cement.

All patients were administered 3 weeks of intravenous antibiotics and 3 weeks of oral antibiotics based on their culture and sensitivity reports.

\section{Procedure}

After selecting the patients based upon the aforesaid criteria, the patients were taken for operation after proper counseling and preanesthetic check-up if needed. Implant removal was performed first. The sinus tracts were injected with methylene blue and were excised till the bone. The fracture site was opened and radical debridement was performed with excision of the infected bone end, scarred soft tissue, and granulation tissue. The intramedullary canal was reamed to the size $2 \mathrm{~mm}$ more than the previous nail size or till the fresh bleeding bone was reached. The reaming and granulation tissue was sent for culture and sensitivity tests. The wound and entire medullary canal were cleaned with $4-5 \mathrm{~L}$ of normal saline. Once debridement was completed, the instruments that were used for the dirty portion of the procedure were removed and the patient's limb was prepared again and draped. The surgeon and the rest of the operating team change all gowns and gloves. The clean portion of the procedure then begins, usually by the surgeon inserting the antibiotic cement-coated nail.
Antibiotic impregnated cement-coated nail was prepared, K-nail for the femur, V-nail for tibia, K-wire for the humerus, and radius was used. We used $2 \mathrm{~g}$ of vancomycin and $2 \mathrm{~g}$ of gentamicin for every $40 \mathrm{~g}$ of bone cement. A higher mix ratio will alter the settling property as also the handling property. An intramedullary nail size $2 \mathrm{~mm}$ less than the largest reamer size used, with a 7- or 8-mm nail was used most commonly. Manual mixing of cement was performed and cement was applied to the nail in a uniformed fashion. The eye of the nail was kept open for easy removal of the nail. Uniform width was achieved by repeatedly passing it from the nail width measuring scale. A fairly smooth surface is obtained by manually rolling and repeatedly checking of width by passing through nail width measuring scale. The nail was kept for 15 minutes in the air for evaporation of monomer.

For beads-the mixture of antibiotic and PMMA and methylmethacrylate is molded or rolled to 3-10 $\mathrm{mm}$ spheres and then strung on to S-S wire no. 20. Antibiotic impregnated cement-coated nails and beads were used for infected nonunion. Retrograde insertion of the nail was done through fracture site for the femur and antegrade insertion for the tibia. In cases with bone defects, approximation of bone ends was attempted. In cases where the fracture site was opened antibiotic-impregnated cement beads were left. Wound cleaning was done and closed in a layer without drain.

\section{Postoperative Protocol}

Removal of stitches was done on the 14th postoperative day. Gentle joint mobilization exercises and muscle strengthening were begun as soon as the cases were comfortable and as tolerated. Gradual weight-bearing generally was given after $>2$ cortex union achieved. All the cases were followed up at 2, 4, 12, 24 weeks, and then 4 weekly for a minimum period of 2 years. Cement beads and nails were removed after 6-12 weeks. Union is assessed by using Stans et al. scale. ${ }^{12}$ The patient were evaluated clinically and radiographically using Stans et al. scale for grading callus formation as a useful indicator of fracture healing (Table 1).

Data analysis was done using a statistical package for social sciences (SPSS) -17.

\section{Results}

In the present study, the majority of the study participants were in the age group of $36-45$ years and the proportion of male participants was comparatively slightly more than female participants. The open fracture was the commonly reported fracture followed by closed fracture and pathological fractures. Also, the femur was the commonly affected bone followed by the tibia, humerus, and radius. Methicillin-resistant Staphylococcus aureus (MRSA) was the common organism isolated followed by Pseudomonas, Escherichia coli, and Klebsiella. In the present study,

Table 1: Grading of callus formation

\begin{tabular}{ll}
\hline Grade 0 & $\begin{array}{l}\text { No identifiable fracture healing } \\
\text { Grade I }\end{array}$ \\
Grade II & $\begin{array}{l}\text { bone formation } \\
\text { Periosteal new bone formation on two sides of the } \\
\text { bone }\end{array}$ \\
Grade III & $\begin{array}{l}\text { Periosteal new bone formation on three or four sides } \\
\text { of the bone }\end{array}$ \\
\hline
\end{tabular}


$90.9 \%$ of cases had complete eradication of infection, $6.8 \%$ of cases had occasional discharge, and $2.3 \%$ of cases had continuous wound discharge (Table 2). Secondary procedures were done for the 40 cured cases and among them, 37 showed complete achievement of union, and 3 cases had occasional discharge and no case had a continuous discharge. Thus, the outcome after the second procedure was $92.5 \%$ of cases had complete healing and $7.5 \%$ of cases had occasional wound discharge (Table 3).

\section{Discussion}

Complete debridement, firm fixation, and the use of high-dose antibiotics are the recommended treatment for infected nonunion of the long bone. ${ }^{1,6,13,14}$ Several procedures have been tried for the

Table 2: Characteristics and outcome after the first procedure

\begin{tabular}{|c|c|c|}
\hline & Frequency & Percentage \\
\hline \multicolumn{3}{|l|}{ Age groups } \\
\hline $16-25$ years & 09 & 20.5 \\
\hline $26-35$ years & 13 & 29.5 \\
\hline $36-45$ years & 22 & 50 \\
\hline \multicolumn{3}{|l|}{ Sex } \\
\hline Male & 24 & 54.5 \\
\hline Female & 20 & 45.5 \\
\hline \multicolumn{3}{|l|}{ Side affected } \\
\hline Right extremity & 25 & 56.8 \\
\hline Left extremity & 19 & 43.2 \\
\hline \multicolumn{3}{|l|}{ Type of fracture } \\
\hline Open fracture & 25 & 56.8 \\
\hline Closed fracture & 12 & 27.3 \\
\hline Pathological fracture & 07 & 15.9 \\
\hline \multicolumn{3}{|l|}{ Bone affected } \\
\hline Femur & 23 & 52.3 \\
\hline Tibia & 16 & 36.4 \\
\hline Humerus & 03 & 6.8 \\
\hline Radius & 02 & 4.5 \\
\hline \multicolumn{3}{|l|}{ Organism isolated } \\
\hline $\begin{array}{l}\text { Methicillin-resistant Staphylococcus } \\
\text { aureus }\end{array}$ & 26 & 59.1 \\
\hline Pseudomonas & 10 & 22.7 \\
\hline Escherichia coli & 07 & 15.9 \\
\hline Klebsiella & 01 & 2.3 \\
\hline \multicolumn{3}{|l|}{ Outcome } \\
\hline Complete eradication of infection & 40 & 90.9 \\
\hline Occasional discharge & 03 & 6.8 \\
\hline Continuous discharge & 01 & 2.3 \\
\hline \multicolumn{3}{|c|}{ Time taken for complete healing (weeks) $(N=40)$} \\
\hline 4-6 weeks & 20 & 50 \\
\hline $6-8$ weeks & 15 & 37.5 \\
\hline $8-10$ weeks & 03 & 7.5 \\
\hline 10-12 weeks & 02 & 05 \\
\hline \multicolumn{3}{|l|}{ Grading of callus formation } \\
\hline Grade 0 & 04 & 9.1 \\
\hline Grade I & 15 & 34.1 \\
\hline Grade II & 19 & 43.2 \\
\hline Grade III & 06 & 13.6 \\
\hline
\end{tabular}

better management of the same and intramedullary devices were used in both primary and secondary stages of infection control ${ }^{8,9}$ and bone healing, ${ }^{15}$ respectively, with remarkable outcomes. ${ }^{16}$

Sinus tract culture reports were negative in some of the studies, where they reported it to have poor diagnostic efficacy. ${ }^{17-19}$ Intramedullary infection is the cause for the nonunion of the fracture is the common complication of ORIF either by intramedullary nailing. ${ }^{20}$ Open fractures have a higher incidence than closed fractures treated with intramedullary nailing. ${ }^{20,21}$ Our series had 20 cases of infected nonunion of which $56.8 \%$ of cases had an open fracture, $27.3 \%$ of cases had closed fractures, and $15.9 \%$ of cases had a pathological fracture due to chronic osteomyelitis at the time of initial injury. At the time of presentation, all the cases of nonunion were due to postoperative infection except one which was pathological fracture due to chronic osteomyelitis. May et al. ${ }^{22}$ classified bone defect into $<6$ and $>6 \mathrm{~cm}$, while Jain and Sinha ${ }^{13}$ proposed a classification of the defect into $<4$ and $>4 \mathrm{~cm}$. We do not include the cases having bone defects $>4 \mathrm{~cm}$, which may be the reason for the good outcome of our study.

In this study, in most of the cases organism isolated from culture and sensitivity report of granulation/necrotic tissue obtained during debridement was MRSA, which was found to be reported in $59.1 \%$ of cases followed by Pseudomonas in $22.7 \%, E$. coli in $15.9 \%$, and Klebsiella in $2.3 \%$ of cases. These findings were compared with the findings of Shyam et al. ${ }^{23}$ who reported that out of 25 cases, Staphylococcus aureus was found in 22 cases. The available studies thus show that MRSA is the most common causative organism of infected nonunion. Thonse and Conway ${ }^{24}$ reported that MRSA was found in $57.69 \%$ of cases followed by other bacteria. The important part of this study is to analyze the prime role of the antibiotic cement-coated nails and cement beads in the control of infection. In this study, a total of 44 cases were treated with antibiotic cement-coated nails and cement beads, at first thorough debridement done and antibiotic cement-coated nail inserted intramedullary and antibiotic cement beads under

Table 3: Outcome after the second procedure

\begin{tabular}{lll}
\hline Secondary procedure & Frequency & Percentage \\
\hline Exchange nailing & 18 & 45 \\
Illizarov fixator & 09 & 22.5 \\
Orthofix & 06 & 40 \\
Plating with bone graft & 07 & 17.5 \\
Outcome after the secondary procedure & & \\
Achieving union & 37 & 92.5 \\
Occasional discharge & 03 & 7.5 \\
Time taken for complete healing (weeks) & & \\
(N=37) & & \\
28-38 weeks & 10 & 27.0 \\
38-48 weeks & 11 & 29.7 \\
$48-58$ weeks & 06 & 16.2 \\
58-68 weeks & 05 & 13.5 \\
68-78 weeks & 03 & 8.1 \\
78-88 weeks & 01 & 2.7 \\
88-98 weeks & 01 & 2.7 \\
Complications & & \\
Joint stiffness & 10 & 25 \\
Cement nail rebonding & 06 & 15 \\
Shortening & 06 & 15 \\
\hline & &
\end{tabular}


subcutaneous tissue overlying fracture site, and skin was closed primarily without drain in $70 \%$ of cases (the cases includes open fracture and pathological fracture) and in remaining $30 \%$ of cases only antibiotic cement-coated nail was used and an incision was closed primarily without drain.

In the present study, we found that out of 44 cases, 40 cases (90.9\%) were completely cured of infection, 3 cases $(6.8 \%)$ had occasional discharge, and 1 case (2.3\%) had a continuous discharge. The mean duration of infection control was 7.4 weeks. Thonse and Conway ${ }^{24}$ had studied antibiotic cement-coated interlocking nails for the management of infected nonunions and segmental bone defects in cases of infected nonunion with bone defects in 20 patients. They reported infection control in $95 \%$ of their study participants. A study conducted by Shyam et al. ${ }^{23}$ reported that all their study cases achieved infection control by using antibioticcoated nails. From these studies, an inference can be made that antibiotic cement-coated nails and cement beads are very effective in controlling infection at the fracture site in cases of infected nonunion with bone defect $<4 \mathrm{~cm}$.

In the present study, we achieved infection control in 40 patients (90.9\%). Among them, additional procedure in the form of exchange nailing with the interlocking nail was done in 18 cases, llizarov fixator in nine cases, orthofix in six cases, and plating with bone graft was done in seven cases. After which union was achieved in 37 cases (92.5\%) out of 40 cases. The mean time for the radiological union was 43.6 weeks. The remaining three $(7.5 \%)$ cases in which we did not achieve union were required additional debridement, curettage, and refixation with bone grafting but the result of these additional procedures was not possible to add in this study because of the short duration of the study. This study shows that antibiotic cement-coated nails were very effective in controlling infection in cases of infected nonunion but could not provide absolute stability to fracture so additional surgery was done to achieve bony union.

The limitation of our study is that we had selected cases with bone defects $<4 \mathrm{~cm}$ only and we had not used cement-coated interlocking nails in our study.

\section{Conclusion}

At the end of our study, we conclude that infected nonunion of long bones can be best treated with the use of antibiotic-coated intramedullary nails and cement beads. Also, it reduces the requirement of wound debridement and provides better stability to the fracture. Duration of control of infection in such cases can be drastically reduced with help of these methods. In some cases without significant bone defects, we can achieve bony union without the need for secondary procedures. Secondary procedures are generally needed to achieve osseous union.

\section{References}

1. Lee SJ, Jang DW, Kim TS, et al. Treatment of chronic osetomyelitis by saucerization and gentamicin-PMMA beads. J Korean Orthop Assoc 1989;24(2):549-556. DOI: 10.4055/jkoa.1989.24.2.549.

2. Court-Brown CM. Fractures of the tibia and fibula. In: Bucholz RW, Heckman JD, Court-Brown CM, ed. Rockwood and Green's fractures in adults. 6th ed., Lippincott Williams and Wilkins; 2006. pp. 2080-2146.

3. Patzakis MJ, Zalavras CG. Chronic posttraumatic osteomyelitis and infected nonunion of the tibia: current management concepts. J Am Acad Orthop Surg 2005;13(6):417-427. DOI: 10.5435/00124635200510000-00006.
4. Buchholz HW, Engelbrecht H. Uber die depotwirkung einiger antibiotica bei vermischung mit dem kunstharz palacos. Chirurg 1970;41(11):511-515.

5. Klemm K. Gentamycin-PMMA-kugeln in der behandlung abszedierender knochen- und weichteilinfektionen. Zentralbl Chir 1979;104(14):934-942.

6. Toh $\mathrm{CL}$, Jupiter JB. The infected nonunion of the tibia. Clin Orthop Relat Res 1995;315(315):176-191. DOI: 10.1097/00003086-19950600000019.

7. Wu CC, Shih $\mathrm{CH}$. Distal tibial nonunion treated by intramedullary reaming with external immobilization. J Orthop Trauma 1996;10(1):4549. DOI: 10.1097/00005131-199601000-00007.

8. Paley D, Herzenberg JE. Intramedullary infections treated with antibiotic cement rods: preliminary results in nine cases. J Orthop Trauma 2002;16(10):723-915. DOI: 10.1097/00005131-20021100000007.

9. Qiang Z, Jun PZ, Jie XJ, et al. Use of antibiotic cement rod to treat intramedullary infection after nailing: preliminary study in 19 patients. Arch Orthop Trauma Surg 2007;127(10):945-951. DOI: 10.1007/s00402-007-0315-x.

10. Maini L, Chadha M, Vishwanath J, et al. The llizarov method in infected nonunion of fractures. Injury 2000;31(7):509-517. DOI: 10.1016/s00201383(00)00036-x.

11. Song HR, Cho SH, Koo KH, et al. Tibial bone defects treated by internal bone transport using the llizarov method. Int Orthop 1998;22(5):293297. DOI: $10.1007 / \mathrm{s} 002640050263$.

12. Stans AA, Morrissy RT, Renwick SE. Femoral shaft fracture treatment in patients age 6 to 16 years. J Pediatr Orthop 1999;19(2):222-228. DOI: 10.1097/01241398-199903000-00017.

13. Jain AK, Sinha S. Infected nonunion of the long bones. Clin Orthop Relat Res 2005;431:57-65. DOI: 10.1097/01.blo.0000152868.29134.92.

14. Struijs PA, Poolman RW, Bhandari M. Infected nonunion of the long bones. J Orthop Trauma 2007;21(7):507-511. DOI: 10.1097/ BOT.0b013e31812e5578.

15. Shahcheraghi GH, Bayatpoor A. Infected tibial nonunion. Can J Surg 1994;37(3):209-213.

16. Eshima I, Feibel RJ, Louie KW, et al. Combined muscle flap and llizarov reconstruction for bone and soft tissue defects. Clin Orthop Relat Res 1996;332(332):37-51. DOI: 10.1097/00003086-199611000-00007.

17. Donati $D$, Biscaglia R. The use of antibiotic-impregnated cement in infected reconstructions after resection for bone tumours. J Bone Joint Surg Br 1998;80(6):1045-1050. DOI: 10.1302/0301620x.80b6.8570.

18. Zuluaga AF, Galvis W, Jaimes F, et al. Lack of microbiological concordance between bone and non-bone specimens in chronic osteomyelitis: an observational study. BMC Infect Dis 2002;16(1):2-8. DOI: 10.1186/1471-2334-2-8.

19. Akinyoola AL, Adegbehingbe OO, Aboderin AO. Therapeutic decision in chronic osteomyelitis: sinus track culture versus intraoperative bone culture. Arch Orthop Trauma Surg 2009;129(4):449-453. DOI: 10.1007/s00402-008-0621-y.

20. Joshi D, Ahmed A, Krishna L, et al. Unreamed interlocking nailing in open fractures of tibia. J Orthop Surg (Hong Kong) 2004;12(2):216221. DOI: $10.1177 / 230949900401200215$.

21. Coles CP, Gross M. Closed tibial shaft fractures: management and treatment complications: a review of the prospective literature. Can J Surg 2000;43(4):256-262.

22. May JW, Jupiter JB, Weiland AJ, et al. Clinical classification of posttraumatic tibial osteomyelitis. J Bone Joint Surg Am 1989;71(9):14221428. DOI: 10.2106/00004623-198971090-00027.

23. Shyam AK, Sancheti PK, Patel SK, et al. Use of antibiotic cementimpregnated intramedullary nail in treatment of infected non-union of long bones. Indian J Orthop 2009;43(4):396. DOI: 10.4103/00195413.55468.

24. Thonse R, Conway J. Antibiotic cement-coated interlocking nail for the treatment of infected nonunions and segmental bone defects. J Orthop Trauma 2008;21(4):258-688. DOI: 10.1097/BOT.0b013e318 03ea9e6. 